\section{Contribuições da semiótica para a análise dos discursos na internet*}

\author{
Contributions of Semiotics for \\ the analysis of discourses on the \\ Internet \\ Lucia TEIXEIRA (UFF) \\ luciatso@gmail.com
}

Recebido em: 17 de dez. de 2019. Aceito em: 05 de fev. de 2019.

*Versão inicial deste artigo foi apresentada como palestra no IV Colóquio Cearense de Semiótica (SEMIOCE) - homenagem a Diana Luz Pessoa de Barros, junho de 2019.

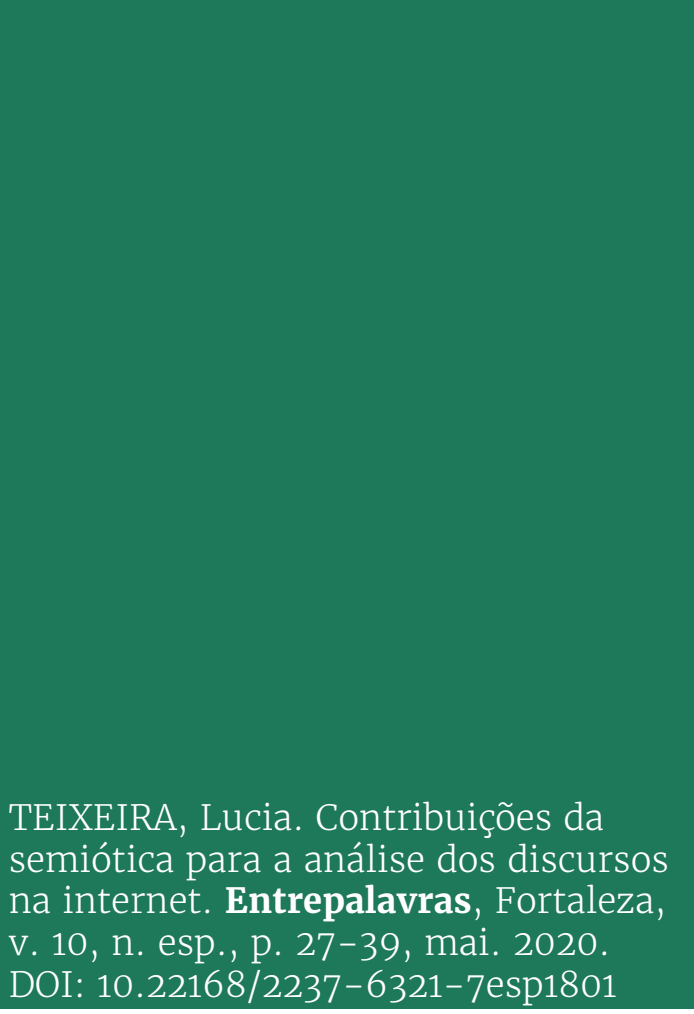

Resumo: $O$ artigo apresenta a contribuição da linguista e semioticista Diana Luz Pessoa de Barros aos estudos sobre o discurso produzido na internet. Com base em artigos da autora, comenta não só a ideia central de suas análises, mas também a exemplaridade de um percurso de pesquisador(a) no campo da linguística. O discurso produzido na internet apresenta, segundo a autora, características de complexidade, compreendida como conceito semiótico que abriga a coexistência de termos contrários. O discurso da internet é complexo em relação às oposições entre língua oral e língua escrita e entre os domínios público e privado. Para formular suas conclusões, a autora percorre trajetória de pesquisa que tem caráter de exemplaridade, seja articulando saberes já sedimentados a novas contribuições teóricas, seja guiando-se por dados observados em corpora variados, seja ainda formulando e sistematizando conceitos ou indicando metodologias que se tornaram referência para a semiótica produzida no Brasil e no mundo.

Palavras-chave: Diana Luz Pessoa de Barros. Discursos na internet. Enunciação. 
10 (esp.)

27-39

mai.

2020

Abstract: The article presents the contribution of linguist and semiotician Diana Luz Pessoa de Barros to studies about the discourse produced on the internet. Based on articles by the author, it comments not only on the central idea of her analysis, but also on the exemplarity of a researcher career in the field of linguistics. The discourse produced on the Internet presents, according to the author, characteristics of complexity, understood as a semiotic concept that houses the coexistence of contrary terms. Internet discourse is complex in relation to the oppositions between oral and written language and between the public and private domains. To formulate her conclusions, the author follows an exemplary research trajectory, either by articulating knowledge already sedimented with new theoretical contributions, or by being guided by data observed in varied corpora, or by formulating and systematizing concepts or indicating methodologies that have become reference for semiotics produced in Brazil and worldwide.

Keywords: Diana Luz Pessoa de Barros. Discourse on the internet. Enunciation.

A cibercultura, entendida não apenas como questão tecnológica, mas como forma de vida da sociedade contemporânea, capaz de gerar impactos socioculturais ainda pouco estudados, manifesta-se por meio de uma linguagem sincrética, que opera com desenhos, gráficos, figuras, cores, palavras, sons, movimento etc. Qualquer que seja o suporte em que se concretiza, a linguagem multissensorial dos novos meios passa a modelar e intermediar relações em que o corpo do homem se dobra aos efeitos, encantos e tentações da máquina. Muitos campos disciplinares debruçam-se sobre o tema, tentando compreender o funcionamento interativo proporcionado pela comunicação via internet, num contexto sócio-histórico em que vigora uma "atitude dispersa, efêmera e hedonista", em meio à "saturação dos metarrelatos e dos grandes sistemas explicativos" (LEMOS, 2007, p.19).

No campo dos estudos linguísticos, muitas análises têm considerado aspectos particulares do funcionamento da rede, como os novos gêneros digitais, as características de informalidade e improvisação da linguagem, as mudanças na escrita, a incorporação de estrangeirismos e neologismos etc. No campo da semiótica, os trabalhos de Diana Luz Pessoa de Barros têm constituído referência sobre o tema, por suas qualidades de abrangência, sistematização e articulação fina entre a descrição linguística e semiótica de procedimentos e a contextualização sócio-histórica da interação.

O conceito de partida para Barros $(2014,2015,2016,2017)$ é o de enunciação. Para a semiótica discursiva, todo enunciado é produto de um ato de linguagem e necessariamente pressupõe uma instância enunciante identificável por meio de marcas deixadas no enunciado. Como em todo ato de linguagem, essa instância enunciante pressuposta, o enunciador, 
se estabelece em uma interlocução com um enunciatário - o perfil de um "para quem" o enunciado foi concebido - igualmente pressuposto ao ato de linguagem em si. O perfil do sujeito da enunciação, portanto, compreende um enunciador e um enunciatário e sua identidade se dá a partir das marcas deixadas no enunciado (FIORIN, 1996).

A característica multilinear do hipertexto (PALÁCIOS, 1999) sugere um problema interessante, pois impossibilita a circunscrição do enunciado, de modo que múltiplas leituras são possíveis porque muitos enunciados são possíveis. Na Web, cria-se uma indefinição quanto à unidade textual, na medida em que um ponto qualquer do hipertexto pode acessar praticamente qualquer outro ponto de qualquer outro hipertexto, não importando suas diferenças em termos de gênero, estilo, enunciatário etc. (NEUMUELLER, 2000). Em linhas gerais, podemos dizer que há uma intertextualidade constitutiva do enunciado que se traduz numa potencialidade aberta pelo enunciador a ser atualizada, pelo enunciatário, num determinado percurso de leitura, caracterizado pelo fluxo e não mais pela circunscrição de um formato (número de páginas, parágrafos etc.). A enunciação se constrói enquanto enuncia, nesse fluxo de conexões, como práxis enunciativa que incorpora novas práticas de leitura, interpretação e produção textual. A ideia de práxis é central na chamada semiótica tensiva (FONTANILLE \& ZILBERBERG, 2001), que procura dar conta do fato de que, além de criar o enunciado, o ato de enunciar cria a própria enunciação. Por outro lado, é preciso salientar que a abertura ilimitada do hipertexto é, de fato, muito mais teórica que prática. É improvável que a partir de um site dedicado à música clássica se tenha acesso a um site sobre astrologia e vice-versa. Embora seja teoricamente possível um espaço web ilimitadamente aberto, a tendência predominante é a de que se criem espaços delimitados em torno de práticas, temas e enunciatários. Buscam-se, na análise dos discursos na internet, as recorrências que, numa totalidade de textos enunciados, criem o efeito de coerência tanto no modo de estruturar os discursos quanto na escolha de temas e figuras e na maneira de organizar o plano de expressão. Esse conjunto de regularidades remete a uma voz, uma presença, um ponto de vista sobre o mundo - uma enunciação.

O projeto desenvolvido no âmbito da ALFAL, sob a coordenação de Diana Luz Pessoa de Barros e de mim mesma, "Enunciação e interação em discursos na internet", vem procurando acolher diferentes orientações teóricas, para consolidar um conjunto de trabalhos 
10 (esp.)

27-39

mai.

2020

descritivos e explicativos do funcionamento da comunicação nas redes digitais. A contribuição de Diana Luz Pessoa de Barros vem orientando o projeto e, por considerar que esse trabalho constitui um exemplo representativo, em seus métodos e conclusões, de toda a produção e do modo de trabalho da linguista que se homenageia neste número da revista Entrepalavras, passo a apresentar algumas notas sobre essa contribuição, sólida em seus parâmetros teóricos e analíticos e essencial para a compreensão dos significados da pesquisa acadêmica.

Tomo como unidade principal de análise o artigo "A complexidade discursiva na internet", publicado na revista CASA, vol.13, em 2015, porque nele me parece estar sistematizado um conceito fundamental para compreender o funcionamento do discurso em circulação na internet, o de complexidade. Incorporo ainda os textos de Barros publicados em 2014, 2016 e 2017, para assinalar o alcance das discussões sobre a intolerância na internet.

Por meio dessas escolhas, sobretudo Barros (2015), tento alcançar a totalidade de uma presença acadêmica e afetiva que honra a universidade, a pesquisa, o trabalho científico e honra todos nós que estudamos e ensinamos semiótica. Os artigos citados me permitirão apresentar não só a clareza e relevância da contribuição da autora, mas também a amplitude de sua reflexão e a exemplaridade de sua trajetória de professora e pesquisadora.

\section{Complexidade discursiva}

Ao analisar o discurso que circula na internet, Barros (2015) usa o conceito de complexidade, tal como definido pela semiótica. Simplificadamente, termos complexos representam a "coexistência de contrários". Assim, o discurso da internet define-se pela "posição intermediária entre a fala e a escrita" e entre o público e o privado.

Dotado de características tanto da fala quanto da escrita, o discurso na internet estabelece um tipo de comunicação que é, ao mesmo tempo, "próxima e distante; descontraída e formal; incompleta e completa; subjetiva e objetiva." (BARROS, 2015) Essa caracterização decorre dos estudos feitos por Barros sobre a relação entre língua oral e língua escrita, desenvolvida em inúmeras publicações, e sistematizada no capítulo "Entre a fala e a escrita: algumas reflexões sobre as posições intermediárias", publicado em 2000 no livro Fala e escrita em questão, organizado por Dino Preti. Nesse texto, Barros mostra "as dificuldades 
de se fazer uma distinção rígida entre escrita e fala" e assinala "a existência de uma certa continuidade e de posições intermediárias entre os pontos extremos em que se caracterizam idealmente língua falada e língua escrita" (BARROS, 2000).

Chamo a atenção aqui para a importância de uma pesquisa que se desenvolve ao longo do tempo, com densidade e coerência. Hoje precisamos produzir quantitativamente, muitas vezes sem tempo para dar consistência a um trabalho. Muitas vezes escrevemos por encomenda, para o tema de um evento, para a proposta de um periódico, esquecendo-nos da verdadeira natureza da pesquisa, que necessita de persistência, aprofundamento, experiência, concentração, vagar e minúcia. Observe-se que um texto publicado em 2000, já derivado de anos de trabalho, retorna em 2015, para tratar de outro tema, num outro momento, em outro tipo de publicação. Mais ainda, o trabalho publicado em 2000 foi realizado no âmbito de um grupo de pesquisa, de encontros em que as pesquisas foram discutidas e refeitas. Decorre, portanto, de parcerias, debates, reformulações e consequentes avanços. Esse trabalho amadurecido na companhia de colegas pesquisadores chega a 2015 também depois de um projeto desenvolvido coletivamente. Dos encontros de trabalho na ALFAL e em mesas coordenadas realizadas em eventos, da discussão em torno de temas variados e de abordagens teóricas diversas, resultaram algumas publicações e muitas questões que continuam a ser discutidas pelos colegas que nos acompanham nesse trabalho coletivo em andamento. Mas a razão de eu estar apresentando aqui esses detalhes da construção de um texto que resulta do trabalho contínuo de uma pesquisadora é justamente a de mostrar que a qualidade do trabalho de pesquisa está submetida não só ao conhecimento particular que um pesquisador adquire e ao qual dá consistência ao longo de sua atuação, mas está também submetida à abertura desse pesquisador para o trabalho do outro, à sua disposição de acolher a fala do outro, sua crítica, seu acréscimo, sua aprovação ou recusa.

Também é importante ressaltar que a autora aqui homenageada faz semiótica porque sabe linguística e faz linguística quando opera com a semiótica. Esse domínio do campo da linguística, que a fez presidente da ABRALIN em gestão admirável e a torna hoje uma das linguistas mais reconhecidas e respeitadas no Brasil, é marca importante dos trabalhos de Barros e permite que todos nós possamos hoje aproveitar, a partir da atuação dela e de José Luiz Fiorin, esse pertencimento àárea da linguística. 
10 (esp.)

27-39

mai.

2020

Barros e Fiorin foram os fundadores da institucionalização da semiótica no Brasil, fortalecendo-a como um GT na ANPOLL, tornando-a um campo de trabalho na ABRALIN e na ALFAL e uma disciplina em muitos cursos de graduação e de pós-graduação. Com isso, foi possível dar visibilidade acadêmica a uma base teórica fundamental para os estudos do texto e do discurso e favorecer o próprio reconhecimento das teorias do texto e do discurso como pertencentes à área dos estudos linguísticos no Brasil.

É justamente porque confere importância a essa herança linguística que Diana Luz Pessoa de Barros examina o discurso complexo da internet tomando como base as categorias de tempo, espaço e pessoa, para dimensioná-las semioticamente.

Em relação ao tempo, ela analisa traços da fala e da escrita "decorrentes da concomitância ou não concomitância da elaboração (planejamento) e da produção do discurso, e da aspectualização do tempo como contínuo (durativo) ou descontínuo (pontual)."

Idealmente, a escrita é planejada antes de sua realização, não apresenta, por isso mesmo, marcas de formulação e de reformulação, e suas unidades duram mais do ponto de vista da dimensão e da complexidade; a fala não é planejada antecipadamente e, por essa razão, apresenta traços de formulação e de reelaboração, e ocorre fragmentada em jatos ou borbotões. Por essas razões, a fala produz, em geral, os efeitos de sentido de informalidade (decorrentes da falta de planejamento e do oferecimento de pistas de sua elaboração e de suas revisões) e de incompletude (o texto vai sendo construído na interação como algo passageiro, que não se conserva), e a escrita, os efeitos contrários de formalidade e acabamento ou completude (BARROS, 2006; 2011, apud BARROS, 2015, p.16).

Assinalo aqui o registro dos trabalhos anteriores que permitiram a densidade da reflexão em 2015, em que Barros associa a fala ao exemplo dos bate-papos na rede (ausência de planejamento, reelaboração e fragmentação) e a escrita aos e-mails (não concomitância temporal e ausência de marcas de reformulação), que variam em grau de formalidade. Essa associação se completa com a identificação dos efeitos de sentido decorrentes da interação na internet:

A informalidade e a incompletude da fala podem ser valorizadas positivamente, pois constroem discursos mais francos, sinceros, subjetivos, cúmplices, atuais, novos, verdadeiros, ou negativamente, porque produzem discursos com envolvimento excessivo, incompletos, mal elaborados, efêmeros. A formalidade e a completude dos discursos da escrita, por sua vez, fazem que eles sejam considerados mais objetivos, 
completos e bem elaborados e acabados ou excessivamente formais e rígidos. Os discursos na internet têm os atributos da fala e da escrita com as valorizações positivas e negativas de ambos. (BARROS, 2015, p.16-17)

Para analisar a categoria de espaço, Diana serve-se do conceito semiótico de presença, estabelecendo o contraste entre presença e não presença dos interlocutores para caracterizar a fala e a escrita, respectivamente. Mostra que tais posições extremas criam os efeitos de proximidade e distanciamento, que serão

valorizados positivamente como cumplicidade, envolvimento afetivo, emocional e corporal, no caso da fala, e como afastamento objetivo e racional, no da escrita. A valoração negativa atribui à fala excesso de intimidade e falta de objetividade, e à escrita, ausência de cumplicidade, de subjetividade e de envolvimento. (BARROS, 2015, p.17)

Se somente essa sistematização já seria importante, Barros complexifica a questão, ao introduzir noções que vêm sendo recentemente tratadas pela semiótica, como as de corpo, afetos e sensações. Mostra a relação entre as ordens sensoriais visual e auditiva na interação na internet e explora a ideia de presença virtual nas redes de conversa. Esse é outro aspecto para o qual eu gostaria de chamar atenção, o da incorporação dos avanços da teoria às análises. O saber consolidado não abre mão da inquietação e da procura. A escolha de novos objetos requer a abertura de novas perspectivas teóricas. Voltarei a isso mais adiante.

A terceira categoria enunciativa a que a análise se refere é a do ator, "termo que trata dos sujeitos investidos pela categoria linguística de pessoa e preenchidos por temas e figuras" (BARROS, 2015, p.18). Ainda remetendo à diferença entre fala e escrita, o texto mostra a alternância de papéis própria da oralidade, criando o efeito de elaboração coletiva da fala, em contraste com o de elaboração individual da escrita.

Num estilo conhecido e admirado, Barros sistematiza o que vem dizendo para avançar em seguida. Diz ela sobre o caráter complexo do discurso da internet, após recorrer a Greimas, Courtès e Brondal para conferir densidade à reflexão:

Definida pela complexidade, a comunicação na internet é, ao mesmo tempo, próxima e distante; descontraída e formal; incompleta e completa; subjetiva e objetiva. Nesse caso, ela tem seus sentidos exacerbados, já que engloba as possibilidades de interação das duas modalidades, de que resultam sua interatividade intensa, a longa conservação de seus conteúdos e a grande extensão de seu alcance. Os estudos de tensividade 


\section{v. 10 (esp.}

27-39

mai.

2020

(FONTANILLE; ZILBERBERG, 2001; ZILBERBERG, 2006a e 2006b) permitem dizer que os discursos na internet dão maior tonicidade a algumas características da fala, mais intensa do que a escrita, como no caso da interatividade, e, ao mesmo tempo, aumentam a extensão da escrita, que dura mais, que não é passageira como a fala, e estendem, assim, seu alcance comunicacional. (BARROS, 2015, p.19)

A entrada do conceito de tensividade e a reflexão sobre as incidências de tonicidade nos discursos na internet põem em causa o ritmo desses discursos e revelam a pesquisadora inquieta, pouco disposta a deixar o saber se acomodar em lugares prontos e estabilizados:

Os estudos de tensividade na semiótica permitem dizer que ela dá maior tonicidade e intensidade a algumas características da fala, como a interatividade, e, ao mesmo tempo, aumenta a extensão da escrita, que dura mais, que não é passageira como a fala e que estende seu alcance comunicacional. (BARROS, 2014, p.3662)

Ao avançar pela semiótica tensiva, Barros estabelece um importante marco nas relações de contrariedade que constituem termos complexos, ao incorporar a noção de concessividade. Se os discursos implicativos constituem-se pela impossibilidade de conjunção entre termos contrários, os discursos concessivos permitiriam essa conjunção. Na internet, os discursos operam, segundo a autora, a conjunção concessiva dos contrários: "fala (próxima, descontraída, incompleta, subjetiva), embora escrita (distante, formal, completa, objetiva) ou escrita embora fala" (BARROS, 2015, p.20). Abre-se aqui um importante caminho de pesquisas, em que se busca a constituição própria dos discursos na internet, recusando-se a simples incorporação de instrumentos metodológicos ou descrições já existentes para outros tipos de discursos mais consolidados. Há um saber acumulado em jogo, que não é imóvel, mas poroso, pronto a ser ressignificado.

Este é mais um aspecto fundamental do trabalho de pesquisa. O conhecimento científico se faz de acúmulo, não de etapas descartáveis. A autora lança mão do conhecimento de base a respeito do conceito de que se serve e vai adiante, trazendo para seu texto a contribuição da semiótica tensiva, que lhe permitirá compreender de modo mais abrangente o objeto de que trata. E na sequência do texto, abrirá um item para falar da organização enunciativa e veridictória dos discursos na internet, retomando a tradição de análise semiótica no tratamento da veridicção, para fundamentar a discussão de questões de autoria e 
anonimato na rede, bem como a relação entre público e privado nesses discursos. Para tratar da primeira questão, recorrerá ao "emprego das categorias enunciativas de pessoa (FIORIN, 1996) e, também, às relações narratológicas que se estabelecem entre enunciador e enunciatário" (BARROS, 2015, p.23). Cita Fiorin, seu companheiro de geração e de desbravamento do campo da semiótica no Brasil, e cita também Norma Discini, de quem foi professora e que ajudou a formar nos cursos de pós-graduação da USP. No final desse texto, ela reconhecerá sua incompletude, própria de todo texto acadêmico, e citará estudos de jovens doutores, como Sandro Torres de Azevedo (2016), que criou o conceito de multibreagem para falar de publicidade em realidade aumentada, mostrando, mais uma vez, sua imensa generosidade acadêmica, que traz para a cena principal da disciplina contribuições ainda pouco conhecidas. Disso também precisa o bom pesquisador: saber atar as pontas, articular contribuições afins, quer decorram de trabalhos consolidados, quer estejam ligadas a pesquisas em desenvolvimento; é preciso confiar no trabalho dos colegas, assimilar e valorizar o trabalho de ex-alunos e dos colegas mais jovens, juntá-los na mesma densa massa de saber necessária ao desenvolvimento de uma análise.

\section{Autoria e anonimato}

Para o estudo da autoria, a semioticista vai mostrar a articulação entre a semântica e a sintaxe, explicando que o sujeito da enunciação, nos discursos na internet:

constrói-se como uma posição sintática e como um ator da enunciação, com identidade, estilo e corpo, preenchido por crenças e valores, modos de ser e de fazer, decorrentes de papéis temáticos e figurativos (DISCINI, 2003, apud BARROS, 2015, p.24).

E, citando Fiorin (1988) para definir as categorias semânticas do discurso, vai dizer, em seguida, que "os temas e as figuras trazem ao ator da enunciação as marcas de sua inserção sócio-histórica e ideológica, e, além disso, como as figuras investem sensorialmente os temas, dão-lhe corpo." (BARROS, 2015, p.24) No entanto, já havia mostrado em outro texto que os efeitos de autoria na internet têm marcas próprias, detendo-se sobre a questão do anonimato:

O anonimato está, porém, em outros textos, relacionado à irresponsabilidade, e, nesse caso, é moralizado negativamente 
v. 10 (esp.)

27-39

mai.

2020

pela sociedade e relacionado à covardia. Em nossa sociedade, a coragem é valorizada. A questão da autoria é fundamental na construção de textos. Para a construção do efeito de autoria são usados nos discursos procedimentos sintáticos e semânticos. As estratégias usadas na sintaxe do discurso dizem respeito ao emprego das pessoas do discurso, acima mencionado, e procuram produzir efeitos de "autoria" (em geral, com o uso do "eu" discursivo) ou de apagamento desse efeito (em geral, com o emprego do ele do discurso). Os recursos semânticos são, principalmente, os da tematização e da figurativização dos atores do discurso, que, em uma totalidade de discursos, constroem o ator da enunciação, com valores, emoções, saberes, crenças, corpo. O anonimato permite a construção do sujeito da enunciação, mas não do ator. A ausência da totalidade discursiva, e, portanto, do ator da enunciação permite apenas a construção do ator narrador de um texto específico. Ora, o narrador é uma voz delegada pelo enunciador, que não tem, portanto a responsabilidade última do discurso que narra. (BARROS, 2014, p.3664)

Nessa citação, a diferença estabelecida entre sujeito da enunciação, posição sintática, e ator da enunciação, posição semântica, constitui ponto de partida instigante para trabalhos futuros, em que a análise de corpora variados permitirá desenvolver em toda a sua complexidade as noções de autoria e anonimato, por meio da relação entre o discurso enunciado e a voz e o corpo depreendidos dessa manifestação. A truculência de discursos que vêm recentemente atacando a universidade pública, por exemplo, ainda que enunciada por um eu multiplicado em inúmeras postagens e declarações, torna-se difusa e apaga a autoria, a voz concreta enunciante, quando a circulação se torna mais extensa e intensifica a replicação irresponsável e a repetição automatizada.

Ao escolher um objeto de pesquisa da comunicação contemporânea, a autora demonstra não só o interesse pelo seu tempo, mas abertura e curiosidade, traços tão essenciais ao trabalho de investigação científica.

Diz Agambem, com enorme propriedade, que

A contemporaneidade (...) é uma singular relação com o próprio tempo, que adere a este e, ao mesmo tempo, dele toma distâncias; mais precisamente, essa é a relação com o tempo que a este adere através de uma dissociação e um anacronismo. Aqueles que coincidem muito plenamente com a época, que em todos os aspectos a esta aderem perfeitamente, não são contemporâneos porque, exatamente por isso, não conseguem vê-la, não podem manter fixo o olhar sobre ela. (AGAMBEN, 2009, p.59.) 
Essa citação admirável, que conforta a todos nós quando nos sentimos envelhecidos, queixosos dos tempos e das modas, serve-me aqui para confirmar o pertencimento político de Diana Luz Pessoa de Barros a seu tempo e também para chamar atenção para a necessidade de visão crítica, às vezes corrosiva, às vezes atenuada, dos tempos que correm, aqui, agora. Em outros artigos (2014, 2016), Barros desenvolverá, também em relação aos discursos na internet, reflexões sobre preconceito e intolerância que fundaram um campo de trabalho na semiótica. São temas mais estritamente políticos, que, tratados com o cuidado teórico necessário, a demonstração dos fatos em corpora específicos e análise criteriosa, contribuem enormemente para a conscientização social dos leitores e impulsionam mudanças de comportamento. Oferecem também fundamentos extremamente relevantes para o ensino, a atuação docente e a interação na escola.

Ao abordar tais temas, Barros assinala que os discursos preconceituosos e intolerantes têm marcas próprias:

Do ponto de vista narrativo, são discursos de sanção aos sujeitos considerados como maus cumpridores de certos contratos sociais; são discursos passionais, em que prevalecem as paixões do ódio e do medo em relação ao "diferente"; desenvolvem temas e figuras a partir da oposição semântica fundamental entre a identidade e a diferença. (BARROS, 2014, p.3660)

A autora comprova, por meio de exemplos variados, que, na internet, exacerbam-se as paixões da intolerância e as manifestações de preconceito, intensificadas em sua manifestação e alargadas na extensão de sua duração (uma postagem, por exemplo, poderá adensarse pelo volume de comentários a ela agregados). Acrescente-se a isso a indistinção entre público e privado, com perda da noção de autoria e diluição da responsabilidade sobre o que se diz. A comunicação em rede amplia as potencialidades do preconceito e da intolerância, ao permitir e naturalizar a circulação livre de mensagens marcadas pelas paixões do ódio, do medo, da vingança, do ressentimento etc.

\section{Conclusão}

Os artigos citados exemplificam muito bem a preocupação de Barros em compartilhar seu saber, sistematizar conceitos, analisar exemplos e acolher avanços teóricos, articulando-os à razoabilidade e importância da tradição, para explicar a operacionalidade da semiótica como teoria que contribui para desvendar os sentidos do texto e do mundo. 
10 (esp.)

27-39

mai.

2020

E se hoje vivemos tempos tão sombrios no país, mais que nunca temos que homenagear os que honram o ensino e a pesquisa, os que dignificam a vida intelectual, os que, estando na universidade, estão em toda parte, porque sua ideia de conhecimento é a do conhecimento compartilhado, aquele que dá a todos oportunidades iguais e quer favorecer os mais desprotegidos.

A pesquisa linguística, como nos mostra Diana Luz Pessoa de Barros, tem dupla responsabilidade: com sua própria constituição teórica densa e consequente e com sua função social, marcada pela consciência de que seu objeto fundamental e mais precioso é a existência humana na linguagem.

\section{Referências}

AGAMBEN, Giorgio. 0 que é o contemporâneo? e outros ensaios. Chapecó, SC: Argos, 2009.

AZEVEDO, Sandro Torres de. Multibreagem: projeções de pessoa, espaço e tempo em discursos publicitários mediados por tecnologias de realidade aumentada. Niterói, UFF, Programa de Estudos de Linguagem, Tese de Doutorado, 2016.

BARROS, Diana Luz Pessoa de. Entre a fala e a escrita: algumas reflexões sobre as posições intermediárias. In: PRETI, Dino. Fala e escrita em questão. São Paulo: Humanitas, 2000. p.57-77.

BARROS, Diana Luz Pessoa de. O discurso intolerante na internet: enunciação e interação. In: XVII Congresso Internacional da Associação de Linguística e Filologia da América Latina - ALFAL, 2014, João Pessoa - PB - Brasil. Estudos linguísticos e filológicos. João Pessoa - PB - Brasil: UFPB/Ideia, 2014. v. 1. p. 3660-3671.

BARROS, Diana Luz Pessoa de. A complexidade discursiva na Internet. CASA: Cadernos de Semiótica Aplicada, v.13, n.2, p.13-31, 2015.

BARROS, Diana Luz Pessoa de. Le discours intolérant sur Internet: tension, signification et énonciation. Sens et médiation. Actes du congrès de l'Ássociation Française de Sémiotique. Paris - França: AFS Éditions, p. 281290, 2016.

BARROS, Diana Luz Pessoa de. Discurso na internet: a complexidade das modalidades falada e escrita na rede social e no jornal on-line. In: LEITE, Marli Quadros (Org.). Oralidade e Mídia. São Paulo: Humanitas, v. 13, p. 159180, 2017.

DISCINI, Norma. 0 estilo nos textos. São Paulo: Contexto, 2003.

FIORIN, José Luiz. Linguagem e ideologia. São Paulo: Ática, 1988.

FIORIN, José Luiz. As astúcias da enunciação. São Paulo: Contexto, 1996. 
FONTANILLE, J.; ZILBERBERG, C. Tensão e significação. São Paulo: Discurso Editorial: Humanitas/FFLCH/USP, 2001.

LEMOS, André. Cibercultura, tecnologia e vida socialna cultura contemporânea. Porto Alegre: Sulina, 2007.

NEUMUELLER, Moritz. Applying Computer Semiotics to Hypertext Theory and the World Wide Web. 2000. Disponivel em: http://www.ifs.unilinz.ac.at/ ifs/staff/reich/ohs6/docs/pp/neumueller/neumueller.pdf > Acessado em 12 fev. 2008.

PALÁCIOS, Marcos. Hipertexto, fechamento e o uso do conceito de nãolinearidade discursiva. 1999. Disponível em: <http://www.comunica. unisinos.br/tics/textos/1999/1999 mp.pdf>. Acessado em 15 nov. 2007.

ZILBERBERG, Claude. Éléments de grammaire tensive. Limoges: Pulim, 2006a.

ZILBERBERG, Claude. Síntese da gramática tensiva. Significação, São Paulo, n.25, p.163-204, 2006b. 